\title{
Toxicological Property of Acetaminophen: The Dark Side of a Safe Antipyretic/Analgesic Drug?
}

\author{
Yoichi Ishitsuka, ${ }^{* a}$ Yuki Kondo, ${ }^{a}$ and Daisuke Kadowaki ${ }^{b}$ \\ ${ }^{a}$ Department of Clinical Chemistry and Informatics, Graduate School of Pharmaceutical Sciences, \\ Kumamoto University; 5-1 Oe-Honmachi, Chuo-ku, Kumamoto 862-0973, Japan: and \\ ${ }^{b}$ Department of Clinical Pharmaceutics, Faculty of Pharmaceutical Sciences, Sojo University; \\ 4-22-1 Ikeda, Nishi-ku, Kumamoto 860-0082, Japan.
}

Received August 27, 2019

\begin{abstract}
Acetaminophen (paracetamol, $N$-acetyl-p-aminophenol; APAP) is the most popular analgesic/antipyretic agent in the world. APAP has been regarded as a safer drug compared with non-steroidal anti-inflammatory drugs (NSAIDs) particularly in terms of lower risks of renal dysfunction, gastrointestinal injury, and asthma/ bronchospasm induction, even in high-risk patients such as the elderly, children, and pregnant women. On the other hand, the recent increasing use of APAP has raised concerns about its toxicity. In this article, we review recent pharmacological and toxicological findings about APAP from basic, clinical, and epidemiological studies, including spontaneous drug adverse events reporting system, especially focusing on drug-induced asthma and pre-and post-natal closure of ductus arteriosus. Hepatotoxicity is the greatest fault of APAP and the most frequent cause of drug-induced acute liver failure in Western countries. However, its precise mechanism remains unclear and no effective cure beyond $N$-acetylcysteine has been developed. Recent animal and cellular studies have demonstrated that some cellular events, such as c-jun N-terminal kinase (JNK) pathway activation, endoplasmic reticulum (ER) stress, and mitochondrial oxidative stress may play important roles in the development of hepatitis. Herein, the molecular mechanisms of APAP hepatotoxicity are summarized. We also discuss the not-so-familiar "dark side" of APAP as an otherwise safe analgesic/antipyretic drug.
\end{abstract}

Key words acetaminophen (APAP); drug-induced asthma; ductus arteriosus; hepatotoxicity; mitochondria; endoplasmic reticulum stress

\section{INTRODUCTION}

Acetaminophen, also called paracetamol or $N$-acetyl-paminophenol (APAP), is an antipyretic/analgesic drug that has been been widely used across the world over more than a century. ${ }^{1,2)}$ It is classed as a mild-to-moderate antipyretic/ analgesic for wide a range of populations (from pediatric, adult, to elderly people) as an ethical clinical medication and also an OTC drug. Recently, APAP has also been used against severe pain, such as cancer pain, as a supportive analgesic or a combination drug with opioid analgesics. A variety of formulations of APAP, such as tablet, capsule, powder, fine granules, syrup (liquid medication), liquid gel, suppository, and injection, are available as ethical and OTC drugs. A recent internet-based questionnaire survey for physicians in Japan reported that APAP was the most prescribed drug among ethical analgesic drugs including non-steroidal anti-inflammatory drugs (NSAIDs), such as loxoprofen, aspirin, ibuprofen, diclofenac, and so on.

Although APAP is undoubtedly a well-recognized and highly used antipyretic/analgesic, clinicians, such as medical doctors, pharmacists, and researchers might actually have a wrong perception regarding it. For example, the adverse reaction profiles of APAP described in package insert in Japan are almost the same as classical NSAIDs and hence some experts have misunderstood that APAP is a type of NSAIDs with weak-to-moderate effects. As some reports have suggested, APAP exerts little effect on peripheral prostaglandin (PG) synthesis compared with NSAIDs and therefore APAP cannot act as an anti-inflammatory drug. ${ }^{2-6)}$ Although the exact pharmacological mechanism of antipyretic/analgesic effects by APAP has yet to be elucidated, $N$-arachidonoyl-aminophenol (AM 404), a metabolite of APAP formed by binding with arachidonic acid, seems to play important roles in the mecha-

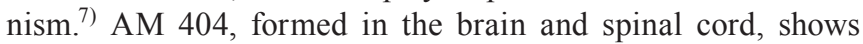
potent analgesic effects through activation of endogenous demulcent receptors, such as cannabinoid receptors type 1 and 2 (CB1 and CB2) and Transient Receptor Potential Vanilloid 1 (TRPV1). ${ }^{8-11)}$ In addition to analgesic effects, APAP also shows anti-pyretic effects possibly through selective inhibition of PGs synthesis in central nervous system (CNS). ${ }^{12-15)}$

Based on these observations, the mode of action by APAP should be distinguished from classical NSAIDs in terms of therapeutic effects and also side (adverse) effects. The lack of inhibition of peripheral PG synthesis by APAP may hypothetically explain the lower risk of adverse reactions induced by classical NSAIDs, such as renal dysfunction, gastrointestinal injury, hemorrhagic tendency, respiratory truck disorder (well known as aspirin asthma), and ductus arteriosus closure in unborn baby. Indeed, APAP has been regarded as the first-line and safer antipyretic/analgesic even in higher-risk population such as the elderly, children, and pregnant women. ${ }^{16-19)}$ However, recently there have been raised some concerns about the safety of APAP in such higher-risk patients. In this article, we review the safety of APAP particularly in terms of respiratory tract and ductus arteriosus-related toxicity. Moreover, we introduce some recent findings about APAP hepatotoxicity, which presents a critical issue of this otherwise safe analgesic/ antipyretic drug to be overcome. 
2. RISK FOR ACUTE KIDNEY INJURY AND GASTROINTESTINAL BY APAP: COMPARISON WITH NSAIDS

NSAIDs generally downregulate central and peripheral PGs synthesis through cyclooxygenase (COX) inhibition and thereby exert analgesic, antipyretic, and anti-inflammatory actions. However, the COX inhibition may also lead to some major adverse effects of NSAIDs, such as gastrointestinal tract injury, hemorrhage due to antiplatelet action, renal injury, respiratory disorders, and so on. ${ }^{20,21)}$ Acute kidney injury (AKI) is a major known adverse effect of NSAIDs; this may be induced by reduction of renal blood flow through the vasoconstriction in afferent arterioles at the glomerulus via inhibition of renal $\mathrm{PGE}_{2}$ or $\mathrm{PGI}_{2}$ synthesis. ${ }^{22)}$ Acute interstitial nephritis induced by an exaggerated immune response after NSAID exposure of approximately 1 week also may be a cause of NSAIDs-induced AKI. Gastrointestinal bleeding due to gastrointestinal disorders (by decreasing $\mathrm{PGE}_{2}$ in gastric mucosa) and antiplatelet activity (decreasing thromboxane $\mathrm{A}_{2}$ in platelets and increasing prostacyclin $\left[\mathrm{PGI}_{2}\right]$ in endothelium) is also a well-known serious adverse effect of NSAIDs. ${ }^{20)}$

As mentioned above, APAP has generally been considered a safer drug than NSAIDs. Are these major side effects of NSAIDs then hardly observed in patients treated with APAP, which is thought little to suppress peripheral PGs synthesis? Indeed, there is little clinical or epidemiological evidence of any relation between APAP and these adverse reactions. In a cohort study in subjects with normal renal function, the relative risk of renal failure was significantly lower in APAP group than NSAIDs. ${ }^{23)}$ Hiragi et al. ${ }^{24)}$ first reported epidemiological evidence for an association between APAP administration and AKI development using self-controlled case series method. They concluded that the results presumably support the general clinicians' impression that APAP is safer for the kidney than NSAIDs.

Recently, big data/real world data analysis has received considerable attention in medical research fields. The Japanese Adverse Drug Event Report (JADER) database is one such database of spontaneous reports of adverse drug reactions in Japan released from Pharmaceuticals and Medical Devices Agency (PMDA). To confirm any association between these major adverse reactions and APAP or NSAIDs therapy in Japanese real-world data, we also reviewed the number of spontaneous reports and the reporting odds ratio, a measure
A) Acute kidney injury

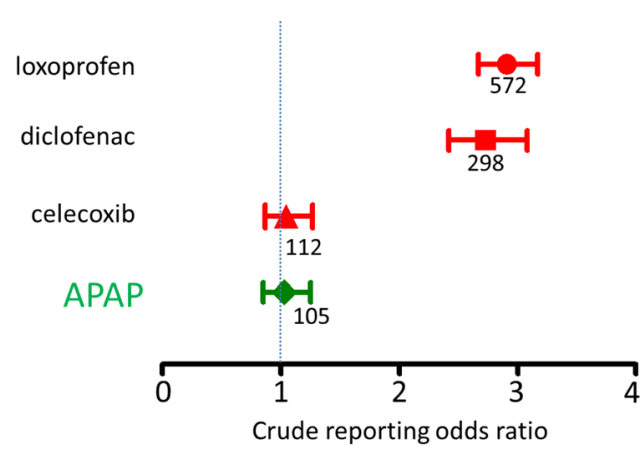

B) Gastrointestinal ulceration

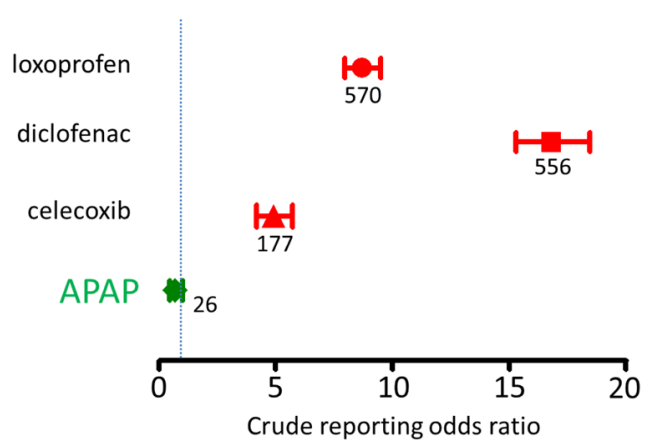

Fig. 1. Comparison of the Reporting Odds Ratio for (A) Acute Kidney Injury and (B) Gastrointestinal Ulceration among Non-steroidal Antiinflammatory Drugs (NSAIDs) and Acetaminophen (APAP) Obtained from Japanese Adverse Drug Event Report (JADER) Database

The JADER database (April 2004 to May 2019) was obtained from the Pharmaceuticals and Medical Devices Agency (PMDA) website (www.pmda.go.jp) and crude reported odds ratio, an authorized pharmacovigilance index for evaluating the risk of adverse drug events in spontaneous reports systems, was calculated according to previously described methods. ${ }^{154)}$ Duplicate data were deleted before the calculation. The standardized Medical Dictionary for Regulatory Activities/ Japanese (MedDRA/J) version Queries (SMQ) version 21.1 was used for the definition of each adverse event as follows "Acute renal failure (narrow scope)" SMQ codes: 20000003 for acute renal injury (Fig. 1A) and "Gastrointestinal ulceration" SMQ codes: 20000106 for gastrointestinal injury (Fig. 1B). Each point represents crude reporting odds ratio and upper (right error bar) and lower (left error bar) $95 \%$ confidence interval. The number shown below each symbol is no. of reported cases. (Color figure can be accessed in the online version.)

of the risk of development of adverse reactions from JADER database. As shown in Fig. 1A, the number of reports related to AKI and the reporting odds ratio of APAP is lower than NSAIDs such as loxoprofen and diclofenac, and almost the

\section{Biography}

Yoichi Ishitsuka is a pharmacist, Board Certified Pharmacist and Supervisor Pharmacists (certificated by the Japanese Society of Pharmaceutical Health Care and Sciences) and Board Certified Drug Safety Director (certificated by the Japanese Society of Drug Safety). He graduated from Daiichi University, College of Pharmaceutical Sciences in 1999. Under the supervision of Professor Tetsumi Irie at Graduate School of Pharmaceutical Sciences, Kumamoto University, he received his M.S. and Ph.D. in 2001 and 2004, respectively. He worked as a staff pharmacist in Department of Pharmacy, Kagoshima University Hospital, under the direction of Professor Katsushi Yamada. He worked as a Research Associate from 2005, a lecturer from 2013, and has been an associate professor at Professor Irie's laboratory since 2016. He has also participated in medical practice and prac-

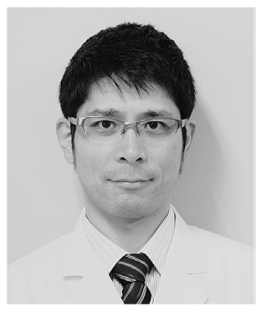

Yoichi Ishitsuka tical training for pharmacy school students at Kumamoto University Hospital. His main research interest is adverse drug reaction, including acetaminophen hepatotoxicity. Recently, he has strenuously conducted the study for new drug development against a rare lysosomal storage disease, Niemann-Pick disease type C (NPC). 
same as celecoxib, a COX-2 selective inhibitor. The data also reflect the reality of APAP-related AKI in Japan. In addition, our previous preclinical study suggests that APAP partly improves renal function in adenine-induced kidney injury model. ${ }^{25}$ Although we need to bear in mind the possibility that APAP may cause chronic renal failure due to renal papillary necrosis, ${ }^{26-29)}$ the above observations support the renal safety of APAP compared with NSAIDs at the moment.

Data from JADER database also suggest safety of APAP in terms of gastrointestinal injury. The number of reports and odds ratio related in gastrointestinal injury by APAP was also lower than other NSAIDs including celecoxib (Fig. 1B). These results seem consistent with a previous study by Nagai et al. ${ }^{30)}$ Risk of gastrointestinal tract injury associated with NSAIDs seems to increase with their potency of COX-1 inhibition. ${ }^{31)}$ In contrast to NSAIDs, APAP is considered to have low potential for peripheral COX inhibition and hence less gastrointestinal toxicity compared with NSAIDs. ${ }^{32,33)}$ The data from JADER database analysis may also reflect the general clinicians' image in gastrointestinal toxicity of NSAIDs and APAP. Real world big data, like JADER database, may give us useful information about the development of major adverse reactions by NSAIDs and APAP. On the other hand, we realized when conducting this research that there may be little epidemiological evidence of any association between APAP and gastrointestinal toxicity. ${ }^{34,35)}$ Epidemiological studies examined "high doses of APAP ( $\geq 2-3 \mathrm{~g} /$ day, chronically)" toxicity and suggest that APAP potentially increases risk of upper gastrointestinal injury. ${ }^{36,37)}$ Even in common adverse reactions, the real picture of APAP seems to remain poorly understood.

\section{POSSIBILITY OF APAP-INDUCED ASTHMA/ BRONCHOSPASM AKIN TO NSAIDS}

NSAIDs-exacerbated respiratory disease (NERD), or generally termed aspirin-exacerbated respiratory disease (AERD), is universally recognized as a severe adverse reaction of NSAIDs. ${ }^{38-40)}$ The etiologic mechanism of NERD/AERD is considered closely related to arachidonic acid cascade, that is, decreasing PGs (particularly in $\mathrm{PGE}_{2}$ ) and increasing cysteinyl leukotrienes (CysLTs) by COX inhibition. ${ }^{40-42)}$ NERD/ AERD typically shows as acute exacerbation of asthmatic symptoms, such as rhinitis, eye watering, lower respiratory symptoms including wheezing and coughing, and progresses to asthmatic attack and nasal polyposis. ${ }^{39,40,43)}$ Based on the pharmacological mechanisms, APAP may be considered as having lower potential for inducing NERD/AERD related syndrome. Indeed, JADER database suggests little signal of asthma induction compared with NSAIDs (Fig. 2). On the other hand, AVICA Clinical Trials, a multicenter, prospective, randomized, double-blind, parallel-group trial in 300 young children with mild persistent asthma suggests no increase in the risk of asthma exacerbation by as-needed use of APAP compared with ibuprofen (not placebo control). ${ }^{44)}$ In addition, Fu et $a l^{45)}$ recently reported that ibuprofen shows a higher risk of asthma exacerbation than APAP among young asthmatic children aged 1-5 years who had severe asthma exacerbation with emergency room visit or hospitalization in the previous 1 year. White and Stevenson ${ }^{40)}$ also advocated that APAP barely induces mild respiratory reactions and only in a minority of patients with NERD/AERD. ${ }^{46)}$ So then, can we consider that

\section{Asthma/bronchospasm}

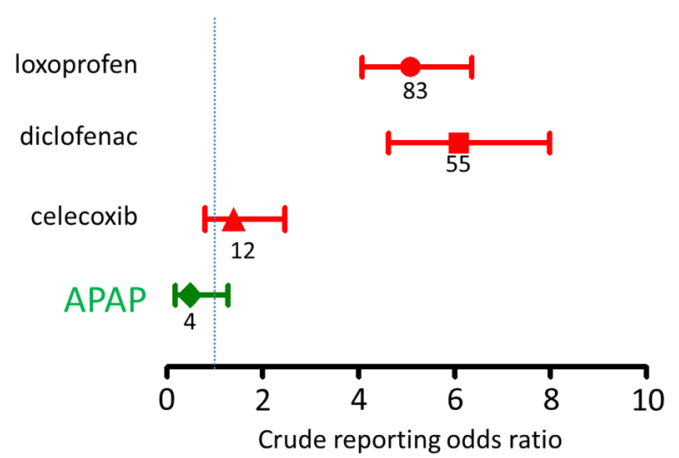

Fig. 2. Comparison of Reporting Odds Ratio for Asthma/Bronchospasm among Non-steroidal Anti-inflammatory Drugs (NSAIDs) and Acetaminophen (APAP) Obtained from Japanese Adverse Drug Event Report (JADER) Database

Data were collected as described in legend of Fig. 1. SMQ version 21.1 was used for the definition of "Asthma/bronchospasm (narrow scope)" SMQ codes 20000025 for drug-induced asthma. Each point represents crude reporting odds ratio and upper (right error bar) and lower (left error bar) 95\% confidence interval. The number shown below each symbol is no. of reported cases. (Color figure can be accessed in the online version.)

APAP really has little risk of inducing asthma? Epidemiologic studies have reported that APAP potentially may cause asthma in adult, children, and prenatal population. ${ }^{47-54)}$ An epidemiological study reported that increasing use of APAP, which has replaced aspirin as the analgesic/antipyretic choice for children, was consistent with an increase in the prevalence of asthma in U.S. children. ${ }^{47)}$ Farquhar et al. ${ }^{52)}$ suggested that patterns of APAP use, such as tendency of high per capita prescription and OTC use, might explain the increased prevalence of asthma and related disorders. Etminan et al. ${ }^{53)}$ in a meta-analysis found a possibility of increased risk of asthma and wheezing in children and adults exposed to APAP. Other systematic reviews and meta-analyses also have supported the possibility of risk of childhood asthma associated with prenatal APAP exposure. ${ }^{54-56)}$ Incidentally, the risk of asthma development related to prenatal exposure of APAP would not be easily detected by spontaneous reports system of adverse reaction such as JADER. So, what is the possible pharmacological and toxicological mechanism of APAP-induced respiratory disease? Tiegs and Arck group ${ }^{57)}$ conducted experimental animal prenatal APAP exposure and demonstrated that APAP induced placental damage, fetal development impairment, and decrease in hematopoietic stem cells in fetal liver, as well as hepatotoxicity in dams. They also reported that the offspring of dams receiving APAP during pregnancy showed a greater susceptibility against airway inflammation induced by antigen challenge. ${ }^{58)}$ Nassini et al. ${ }^{59)}$ demonstrated that therapeutic doses of APAP into mice produced detectable levels of $\mathrm{N}$ acetyl- $p$-benzoquinone imine (NAPQI), a highly reactive toxic metabolite of APAP, in the lungs, and showed inflammatory response, such as neutrophil infiltration and chemokine expression in the airways through transient receptor potential ankyrin-1 (TRPA1) channel dependent pathway. These preclinical trials may explain the mechanisms of APAP-induced respiratory disease. Clinical findings also may indicate the participation of oxidative stress, such as maternal antioxidant gene polymorphisms ${ }^{60)}$ and glutathione pathway $^{61)}$ in relation between prenatal APAP exposure and childhood asthma. On 
the other hand, there is some controversial experimental and epidemiologic evidence. Smith et al. ${ }^{62)}$ argued that APAP can attenuate allergic airway inflammation induced by house dust mite in mice. Kennedy et $a .^{63)}$ reported that APAP exerts bronchodilatory and bronchoprotective effects in human precision cut lung slice airway system. Cheelo et al. ${ }^{54)}$ reported in a meta-analysis of cohort studies that APAP exposure in pregnancy is related to increased risk of childhood asthma; however, marked heterogeneity among the studies and respiratory tract infections may have been significant confounders. In a recent review, Lourido-Cebreiro et al. ${ }^{64)}$ also claimed that risk of asthma related to prenatal APAP exposure is explainable by confounding factors and therefore the evidence remains inconclusive. Hence the respiratory toxicity of APAP exposure remains controversial. Further clinical evaluation of this issue in the form of randomized control trials will be implausible because of ethical and practical difficulties. ${ }^{35,54)}$ Development of innovative techniques will be needed to solve this presently intractable problem.

\section{PHARMACOLOGICAL/TOXICOLOGICAL ACTION OF APAP ON DUCTUS ARTERIOSUS, AKIN TO NSAIDS?}

Ductus arteriosus is a blood vessel connecting the pulmonary artery to the proximal descending aorta in fetus. It is essential for bypassing blood flow from non-functioning lungs throughout the fetal period. In the normal condition, ductus arteriosus is immediately closed after birth when spontaneous respiration commences. $\mathrm{PGs}$, particularly $\mathrm{PGE}_{1}$ and $\mathrm{E}_{2}$, play important roles to maintain patency of the ductus arteriosus during fetal development stage by dilating vascular smooth muscle. Therefore drugs that affect PG synthesis, such as NSAIDs, can induce premature closure of the fetal ductus arteriosus as an adverse reaction to maternal intentional or unintentional ingestion. ${ }^{65)}$ Would APAP, which little affects COX activity in peripheral organs, potentially induce constriction of ductus arteriosus? El-Khuffash et al. ${ }^{66)}$ demonstrated using their ex vivo experimental system that isolated ductus arteriosus from preterm mice or term gestation mice displayed limited response to increasing concentrations of APAP, but showed significant concentration-dependent constriction in response to indomethacin. Indomethacin also significantly inhibited 6-keto $\mathrm{PGF}_{1} \alpha$, the stable metabolite of $\mathrm{PGI}_{2}$ or $\mathrm{PGE}_{2}$ production in freshly isolated term gestation ductus explants compared with APAP. ${ }^{66)}$ These data suggest that APAP potentially has little effect on ductus arteriosus compared with NSAIDs. Indeed, APAP is widely considered a safer antipyretic and analgesic than NSAIDs during pregnancy. ${ }^{67)}$ However, at least one case of in utero ductal closure following APAP exposure during late pregnancy has been reported. ${ }^{68)}$ It is also noteworthy that real-world evidence in JADER database includes a couple cases of fetal ductus arteriosus closure by APAP and the number of reports was higher than for NSAIDs (Fig. 3). These data indicate the possibility of fetal ductal closure as an adverse event of APAP.

Opposite to fetal ductus arteriosus closure, failure of ductus closure after birth, that is patent ductus arteriosus, sometimes requires pharmacologic closure by administering NSAIDs. Therefore indomethacin or ibuprofen have been used as effective drugs for the treatment of patent ductus arteriosus in neo-

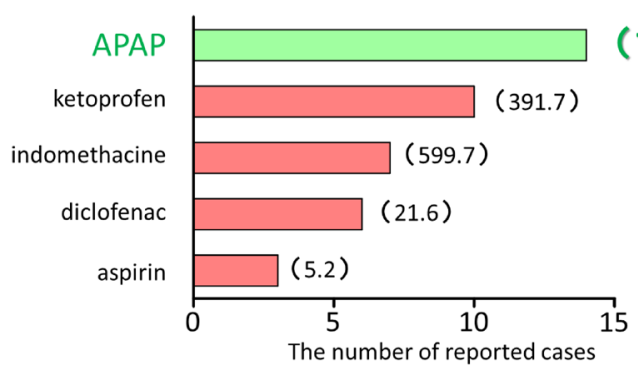

(71.0)

Fig. 3. No. of Cases Diagnosed with Premature Closure of Arterial Duct as Adverse Drug Events by Pre-natal Exposure of Non-steroidal Anti-inflammatory Drugs (NSAIDs) and Acetaminophen (APAP) Spontaneously Reported to the Japanese Adverse Drug Event Report (JADER) Database

Each bar represents no. of reported cases. The number shown on right side of each symbol is reporting odds ratio. (Color figure can be accessed in the online version.)

natal care units all over the world. ${ }^{69-71)}$ NSAIDs have a pharmacological potential of ductus arteriosus constriction through inhibition of COX activity. Interestingly, recent clinical studies reported some potential of APAP as an effective treatment for patent ductus arteriosus in preterm newborns. ${ }^{72-75)}$ Härkin et $a l^{76)}$ demonstrated that prophylactic APAP exerts early closure of the ductus arteriosus in a controlled, doubleblind, phase I-II trial in very low gestational age ( $<32$ weeks) infants requiring intensive care. Some recent studies have also suggested a possibility of APAP as an alternative to indomethacin or ibuprofen for the treatment of patent ductus arteriosus. $^{74,75,77,78)}$ Some pediatricians and researchers have commented on the topics. ${ }^{79,80)}$ APAP may become a hoped-for safer drug for preterm newborn patients than indomethacin or ibuprofen in terms of adverse effects, such as renal failure. On the other hand, a recent pilot study reported that no ductus closure was observed even in cases treated with high doses of APAP and suggested that monitoring of serum APAP concentration might be critical. ${ }^{81)}$ In addition, some reports alert that use of APAP still raises concerns of neurodevelopment, such as autism spectrum disorder and cognitive decline. ${ }^{2,82-84)}$ From a perspective of basic pharmacology and toxicology, the mechanism of ductus constriction by APAP is also still unclear. Therefore further basic and clinical study is warranted.

\section{APAP-INDUCED LIVER INJURY: A CLASSIC BUT UNSOLVED TOXICITY OF A SAFE DRUG}

\subsection{Background of APAP-Induced Liver Injury}

Hepatotoxicity is the most well-known severe adverse effect of APAP. APAP, particularly in case of overdose, can induce severe hepatic injury in rodent and human with high reproducibility. Interestingly, some studies show that one of the most frequent causes of acute liver failure in the U.S.A. is intentional or unintentional APAP overdose. ${ }^{85,86)}$ APAP hepatitis is also a serious social issue in European and Asian countries. ${ }^{87-89)}$

Generally, drug-induced liver injury (DILI) develops due to immunoreaction. Meanwhile APAP, particularly in cases of overdose, characteristically shows direct hepatocellular injury. ${ }^{90)}$ Centrilobular hepatocellular necrosis is a typical pathological characteristic of APAP hepatotoxicity, ${ }^{91)}$ initiated by a reactive metabolite of APAP, NAPQI, ${ }^{92}$ mainly produced by CYP 2E1. ${ }^{93-95)}$ NAPQI can injure hepatocytes 


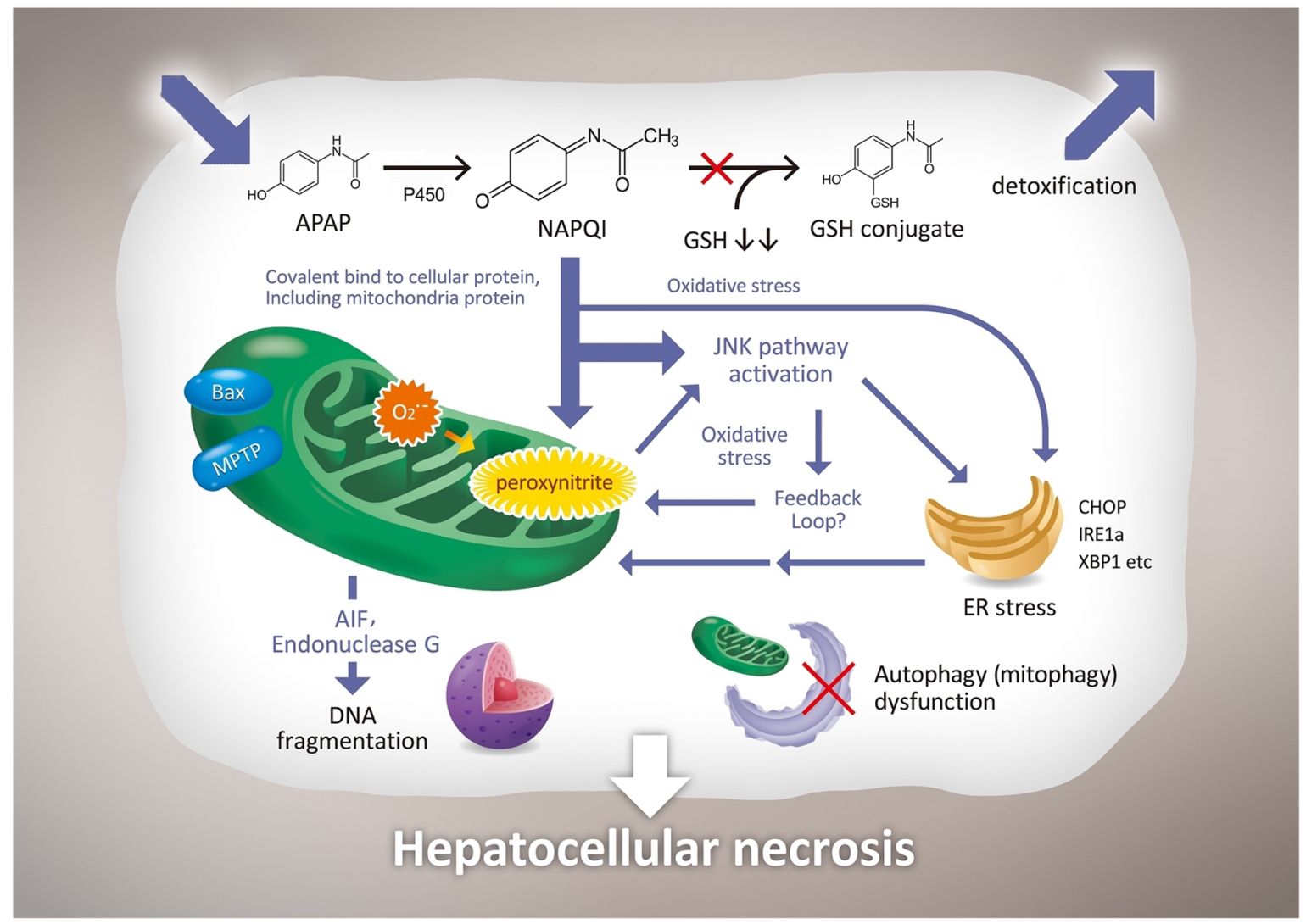

Fig. 4. Proposed Mechanisms of Acetaminophen (APAP)-Induced Hepatocellular Injury

Overdosed APAP can produce $N$-acetyl- $p$-benzoquinoneimine (NAPQI), a toxic metabolite, through cytochrome P450 (mainly CYP2E1). In the normal (therapeutic doses) condition, NAPQI is detoxified with glutathione (GSH). On the other hand, massive amount of NAPQI produced during overdose can lead to GSH depletion and consequently binding to cellular proteins, such as mitochondrial protein, which initiates hepatocellular necrosis with DNA fragmentation (see section 5.2.1). NAPQI induces some critical events, such as mitochondrial dysfunction (5.2.2) and c-jun N-terminal kinase (JNK) pathway activation (5.2.3), and other events, such as autophagy (mitophagy) and endoplasmic reticulum (ER) stress (5.2.4). (Color figure can be accessed in the online version.)

with oxidative and nitrosative stress, and inflammation. The proposed mechanisms of APAP hepatitis is shown in Fig. 4. In therapeutic doses and generally healthy condition, NAPQI would conjugate with glutathione then detoxify (the conjugation product eliminated through renal excretion). On the other hand, massive NAPQI formed in the liver of overdosed patients or chronic alcohol abuse patients can cause glutathione depletion and NAPQI rapidly binds to cellular proteins resulting in severe hepatocellular injury. $N$-Acetylcysteine (NAC) has been ethically used as the only approved antidote against APAP hepatotoxicity. The hepatoprotective molecular mechanism of NAC against APAP overdose is mainly considered as supplementation of depleted glutathione and detoxifying of NAPQI, which relatively locates upstream of APAP hepatocellular injury mechanisms. NAC sometimes shows limited hepatoprotective effects in APAP-overdose patients because of delay in starting treatment. Therefore development of a novel effective antidote that can act at other key mechanisms located downstream of APAP hepatocellular injury is needed. That compound would also be expected to exert hepatoprotective effects even in the case of delayed start to treatment.

\subsection{Molecular Mechanisms of APAP-Induced Liver} Injury

5.2.1. DNA Fragmentation during APAP-Induced Liver Injury

From pathological and morphological viewpoints, hepatocellular injury induced by APAP is defined as centrilobular "necrosis" with swelling of liver cells and karyolysis; however, in this setting cell death is developed through complicated mechanisms such as programmed necrosis or necroptosis. ${ }^{90,91)}$ APAP-induced hepatocyte death is necessarily accompanied with DNA fragmentation as evidenced by histologic and biochemical analysis, such as terminal deoxynucleotidyl transferase deoxyuridine triphosphate (dUTP) nick end labeling (TUNEL) assay and anti-histone enzyme-linked immunosorbent assay (ELISA) assay. However, caspase family, such as caspase 3, seems little to contribute to DNA damage during APAP hepatotoxicity. ${ }^{96,97)}$ Some previous studies have concluded no critical roles of apoptosis in the development of APAP-induced liver injury. Jaeschke and colleagues have implicated misunderstanding of researchers who wrongly conclude the mechanisms of APAP hepatotoxicity based on measurement of a few and assumed apoptosis parameters. ${ }^{90}$ ) DNA fragmentation in APAP hepatotoxicity seems executed by apoptosis-inducing factor (AIF) and endonuclease G, which are released from outer membrane permeabilized mitochondria by cellular signaling induced by NAPQI. ${ }^{98,99)}$ Bajt et al. ${ }^{99)}$ indicated the importance of AIF in the development of APAP hepatotoxicity using Harlequin mouse, a model of partial AIF deficiency (approximately 10-20\% compared with wild-type mouse). In that study, Harlequin mice showed lower degree of hepatic DNA damage, necrosis, and serum transaminase elevation than wild-type mice, while other parameters located upstream of the hepatotoxic mechanisms than DNA fragmen- 
tation, such as mitochondrial oxidative stress, mitochondrial membrane permeability, and c-jun N-terminal kinase (JNK) phosphorylation, were also drastically attenuated.

5.2.2. Roles of Mitochondria in APAP-Induced Liver Injury and Possibility as Target Organelle for Development of Effective Treatment

Mitochondria play a major role in APAP-induced liver injury; that is, mitochondrial membrane permeability transition can lead to release of AIF, endonuclease G, and cytochrome C into cytoplasm, which initiates DNA damage and necrotic cell death. ${ }^{98-100)}$ A reactive metabolite of APAP, NAPQI, forms adducts with mitochondrial proteins then initiates mitochondrial dysfunction and hepatocytic necrosis. However, the singularly responsible target protein for NAPQI has not been identified yet. ${ }^{101)}$ Mitochondrial injury by adducts formation seems to trigger breakdown of mitochondrial membrane potential with redox condition and hepatotoxicity. ${ }^{102)}$ The importance of mitochondrial damage in the development of APAP hepatotoxicity vigorously has been demonstrated. For instance, preventive effects of inhibition of mitochondrial permeability transition pore (MPTP) opening by cyclosporin A against APAP liver injury in mouse model ${ }^{100)}$ and in cellular model ${ }^{103,104)}$ have been reported. MPTP opening seems activated by phosphorylated JNK translocation into mitochondria ${ }^{105)}$ and some factors, such as translocated Bcl-2-associated X (Bax), $\left.{ }^{106}\right)$ cyclophilin $\mathrm{D},{ }^{107,108)}$ and iron ion, ${ }^{109,110)}$ seem also involved. Dysfunction of mitochondrial respiratory chain and induction of mitochondrial oxidative stress, which accompany superoxide and subsequent reactive radical peroxynitrite production, are also critical factors in APAP hepatotoxicity. ${ }^{108,111,112)}$ Moreover, recent reports on riddance of damaged mitochondria by mitophagy have confirmed the pathophysiological importance of mitochondria. ${ }^{113)} \mathrm{Ni}$ et al. ${ }^{114)}$ demonstrated protection from APAP hepatotoxicity by removing APAP protein adducts by autophagy in mouse model. Wang et al. ${ }^{15)}$ also reported that double deletion of PINK1 and Parking impaired mitophagy pathway and hence exacerbated APAP-induced liver injury and mortality in mice.

A number of pharmacological studies also support the responsibility of mitochondria in APAP hepatotoxicity (Table 1). For example, significant hepatoprotection afforded by MitoTEMPO, a mitochondrial targeted antioxidant, was reported by Jaeschke's group. ${ }^{116,117)}$ In addition, pleiotropic action of ethical drugs to mitochondria, such as metformin ${ }^{118)}$ and methylene blue, ${ }^{119)}$ were identified. Furthermore, a curious recent approach, such as mitochondria replacement or transplantation, has been proposed as possible treatment against APAPinduced liver injury. ${ }^{120}$ Mitochondria may be a signaling hub organelle of numerous critical cellular events during APAPinduced liver injury. Prevention of mitochondrial damage or quenching of injured mitochondria may be attractive targets for effective therapy against APAP hepatotoxicity.

5.2.3. Roles of JNK in APAP-Induced Liver Injury

JNK is a member of mitogen-activated protein kinase (MAPK) family and implicated in signaling of inflammatory or cellular stress response. ${ }^{124-126)}$ JNK is considered a key mediator in the development of APAP hepatotoxicity. ${ }^{127)}$ Indeed, several reports evaluated the effects of JNK pathway inhibition in this context. Gunawan et al. ${ }^{128)}$ reported remarkable protective effects of SP600125, a chemical JNK inhibitor, on APAP-liver injury in mice. They also confirmed the hepatoprotection by knockdown of Jnk2 using antisense oligonucleotide (ASO) pretreatment and Jnk2 gene knockout. However, they observed no hepatoprotection in Jnk1 ASO pretreatment or gene knockout mice. Henderson et al. ${ }^{129)}$ demonstrated JNK activation in the liver of patients with APAP hepatotoxicity and significant hepatoprotective effects by a peptide inhibitor d-JNKI1 as well as SP600125 in their mouse model. On the other hand, they also observed no protective effect of Jnk1 or Jnk2 gene knockout against APAP-induced liver injury in their mouse model. Latchoumycandane et al. ${ }^{130)}$ found that leflunomide, a disease-modifying anti-rheumatic drug, can inhibit JNK phosphorylation and predominantly attenuate APAP-induced liver injury. Besides, studies that evaluated the effects of inhibition or gene deletion of upstream kinases, such as apoptosis signal-regulating kinase 1 (ASK1), ${ }^{131-133)}$ glycogen synthase kinase $3 \beta(\mathrm{GSK} 3 \beta),{ }^{134)}$ and mixed lineage kinase 3 (MLK3), ${ }^{135)}$ also support important roles of JNK in the development of APAP-induced liver injury. However, controversial argument about the role of JNK in APAP hepatotoxicity has been also raised. Contradictory results about the effects of Jnk1 or Jnk2 gene deletion were reported. ${ }^{129,136)}$ In addition, some effective reagents, such as 4-phenylbutyrate (4-PBA; a chemical chaperon/ER stress inhibitor), ${ }^{137)}$ or factors/genes, such as CCAAT/enhancer-binding protein homologous protein (CHOP), which can independently work on APAP hepatotoxicity without accompanying JNK activation, have been identified. ${ }^{138)}$ Although many studies have further confirmed remarkable preventive effects of SP600125 on APAP hepatotoxicity in vitro and in vivo, recently Cubero et al. ${ }^{139)}$ indicated the possibility of off-target hepatoprotective effects by SP600125.

5.2.4. Other Possible Key Mediators and/or Organelles in APAP-Induced Liver Injury

Autophagy, including mitophagy, seems to play important roles in hepatocellular protection during APAP-induced liver

Table 1. Reported Mitochondria Selective Drugs and Methods That Exert Protective Action against APAP Liver Injury Models

\begin{tabular}{llc}
\hline \hline Drugs /Methods & \multicolumn{1}{c}{ Mechanism } & Ref. \\
\hline Mito-TEMPO & Mitochondria-targeted antioxidant & $116,117)$ \\
Metformin & Inhibiting mitochondrial complex I activity & $118)$ \\
Methylene blue & Bypassing NAPQI-inhibited mitochondrial complex II activity & $119)$ \\
Resveratrol & Inhibiting MPTP without prevention of JNK activation & $121)$ \\
MCJ small interfering RNA & Inhibiting MCJ, an endogenous negative regulator of complex I & $122)$ \\
Ru360, minocycline & Inhibiting iron uptake into mitochondria & $110)$ \\
SRT1720 & Inducing mitochondrial biogenesis & $123)$ \\
Mitochondrial transplantation & Replacing dysfunctional mitochondria with functional exogenous mitochondria & $120)$ \\
\hline
\end{tabular}


injury. $\mathrm{Ni}$ et $a .^{140)}$ demonstrated that activation of autophagy-related events, evaluated by histological findings, such as inclusion of injured mitochondria by double membrane autophagosomes, and biochemical measurements, such as PE-conjugated form of light chain 3 (LC3-II) and p62 levels, occur in APAP-overdosed mouse liver and in primary cultured hepatocytes. They also showed that pharmacologic autophagy induction or inhibition using rapamycin or chloroquine respectively attenuated or exacerbated APAP-induced hepatotoxicity in mice. Around the same time, Igusa et al. ${ }^{141)}$ reported an enhancement of APAP-induced liver injury in Atg7-deficient mice, and suggested a pivotal role in protection against APAP-induced liver injury through removal of damaged mitochondria and oxidative stress. Although liver-specific conditional Atg7-deficient mice induced by polyinosinic acid-polycytidylic acid have some weakness, the conclusion in both studies is almost same. Recently, Wang et al. ${ }^{115)}$ reported that PINK1-Parkin signaling pathway plays a critical role in APAP-induced mitophagy and liver injury. Based on these data, it would be considered that autophagy or mitophagy exerts protective roles during APAP-induced liver injury.

The endoplasmic reticulum (ER) is an important organelle in cellular response during inflammation and cellular stress. ER stress may be also involved in the pathophysiology of drug-induced organ injury (adverse reaction) models, such as renal $^{142)}$ and lung injury. ${ }^{143-146)}$ Recent reports suggest that ER stress and ER stress-related molecules participate in the development of APAP-induced liver injury. Nagy et al. ${ }^{147,148)}$ showed significant induction of an ER stress-responsive proapoptotic transcription factor CHOP, also known as growth arrest- and DNA damage-inducible gene 153 (GADD153) or DNA damage-inducible transcript 3 protein (DDIT3), in mouse APAPinduced liver injury model. In our previous study, we also demonstrated that chemicals that have attractive hepatoprotective effects, such as the selective thromboxane $A_{2}$ synthase inhibitor ozagrel and ER stress inhibitor 4-PBA drastically reduce Chop mRNA and protein expression. ${ }^{137,149)}$ Uzi et al. ${ }^{138)}$ reported a role of CHOP as critical regulator in APAP hepatotoxicity using Chop gene-deficient mice. Other studies also showed significant induction of Chop mRNA and/or protein in mouse liver injured by APAP overdose. ${ }^{150,151)}$ In addition, Hur et $a{ }^{152)}$ demonstrated that inositol-requiring transmembrane kinase/endoribonuclease $1 \alpha(\mathrm{IRE} 1 \alpha)$, a mammalian stress sensor, participates in APAP-induced ER stress response during liver injury through regulation of its downstream transcription factor X-box binding protein 1 (XBP1) and Cypla2 and 2e1 mRNA expression. We also provided histological evidence of XBP1 splicing around the injured hepatic zonal area in timedependent manner after APAP overdose in ER stress-activated indicator (ERAI) transgenic mice. ${ }^{137)}$ A recent report also suggests that upregulation of steroidogenic acute regulatory protein (STARD1), a mitochondrial cholesterol transporter, following ER stress mediates APAP hepatoxicity via mitochondrial SH3BP5 (SAB) and JNK1 and 2 phosphorylation. ${ }^{153)}$ Other ER stress and unfolded protein response-related factors, such as activating transcription factors 3 and 4 and endoplasmic reticulum-localized DnaJ 4, also seem elevated in APAP hepatotoxicity. ${ }^{138,152)}$ These experimental findings suggest that ER stress and related molecular events occur in liver injury and their regulation using chemical chaperons such as 4-PBA and tauroursodeoxycholate would be a possible candidate for effective treatment against APAP-induced liver injury. ${ }^{137,150,151)}$

\section{CONCLUSION}

APAP may be safer than NSAIDs as an analgesic/antipyretic agent. However, the recent increasing use and/or dose of APAP is accompanied by further concerns about the potential toxicity of APAP. The possibility of asthma/bronchospasm induction as a pre-natal toxicity of APAP exposure should be borne in mind, while relations between APAP therapy and induction of asthmatic disorder have not been conclusively demonstrated and their precise mechanisms remain unclear. Recent clinical and epidemiologic data indicate pharmacologic and toxicologic action of APAP on ductus arteriosus, and this may relate to ductus arteriosus closure as a pre-natal adverse reaction of APAP as well as therapeutic potential against patent ductus arteriosus in neonates. However, based on these observations, the U.S. Food and Drug Administration (FDA) has recommended against APAP use in pregnant women since 2015. The biggest weakness of APAP would be hepatotoxicity. Recent evidence has indicated that mitochondrial dysfunction, ER stress, JNK pathway activation, and so on seem to play important roles in APAP hepatotoxicity. More research to identify the exact mechanisms of APAP hepatitis and to develop effective treatments is warranted. APAP is the most popular and safe analgesic/antipyretic agent. On the other hand, the "dark side" of APAP remains unclear until further basic and clinical evaluation elucidates this conundrum.

Acknowledgments We would like to express our deepest gratitude to Prof. Tetsumi Irie (Kumamoto University) for supervision to achieve the results described in this review. We are also most grateful to Prof. Sumio Hirata (Kumamoto University) for helpful discussions and substantive advice and to all our collaborators for their support. We thank Luminary Medical K.K. for useful discussion about JADER database analysis using DRiFOs ${ }^{\circledR}$ online system. We also appreciate Mr. Michisuke Ohira and Mr. Kota Matsuoka (9DW Corporation) for their technical support to analyze JADER database. Our work described here was supported by a Grant-in-Aid for Young Scientists (B), and for Scientific Research (C) from the Ministry of Education, Culture, Sports, Science and Technology of Japan.

Conflict of Interest The authors declare no conflict of interest.

\section{REFERENCES}

1) Brodie BB, Axelrod J. The fate of acetanilide in man. J. Pharmacol. Exp. Ther., 94, 29-38 (1948).

2) Ghanem CI, Pérez MJ, Manautou JE, Mottino AD. Acetaminophen from liver to brain: New insights into drug pharmacological action and toxicity. Pharmacol. Res., 109, 119-131 (2016).

3) Warner TD, Giuliano F, Vojnovic I, Bukasa A, Mitchell JA, Vane JR. Nonsteroid drug selectivities for cyclo-oxygenase-1 rather than cyclo-oxygenase-2 are associated with human gastrointestinal toxicity: a full in vitro analysis. Proc. Natl. Acad. Sci. U.S.A., 96, 7563-7568 (1999).

4) Vane JR. Inhibition of prostaglandin synthesis as a mechanism of action for aspirin-like drugs. Nat. New Biol., 231, 232-235 (1971).

5) Flower RJ, Vane JR. Inhibition of prostaglandin synthetase in 
brain explains the anti-pyretic activity of paracetamol (4-acetamidophenol). Nature, 240, 410-411 (1972).

6) Engström Ruud L, Wilhelms DB, Eskilsson A, Vasilache AM, Elander L, Engblom D, Blomqvist A. Acetaminophen reduces lipopolysaccharide-induced fever by inhibiting cyclooxygenase-2. Neuropharmacology, 71, 124-129 (2013).

7) Högestätt ED, Jönsson BAG, Ermund A, Andersson DA, Björk H, Alexander JP, Cravatt BF, Basbaum AI, Zygmunt PM. Conversion of acetaminophen to the bioactive $N$-acylphenolamine AM404 via fatty acid amide hydrolase-dependent arachidonic acid conjugation in the nervous system. J. Biol. Chem., 280, 31405-31412 (2005).

8) Beltramo M, Stella N, Calignano A, Lin SY, Makriyannis A, Piomelli D. Functional role of high-affinity anandamide transport, as revealed by selective inhibition. Science, 277, 1094-1097 (1997).

9) De Petrocellis L, Bisogno T, Davis JB, Pertwee RG, Di Marzo V. Overlap between the ligand recognition properties of the anandamide transporter and the VR1 vanilloid receptor: inhibitors of anandamide uptake with negligible capsaicin-like activity. $F E B S$ Lett., 483, 52-56 (2000).

10) Szallasi A, Di Marzo V. New perspectives on enigmatic vanilloid receptors. Trends Neurosci., 23, 491-497 (2000).

11) Zygmunt PM, Chuang H, Movahed P, Julius D, Högestätt ED. The anandamide transport inhibitor AM404 activates vanilloid receptors. Eur. J. Pharmacol., 396, 39-42 (2000).

12) Riedel W, Lang U, Oetjen U, Schlapp U, Shibata M. Inhibition of oxygen radical formation by methylene blue, aspirin, or alphalipoic acid, prevents bacterial-lipopolysaccharide-induced fever. Mol. Cell. Biochem., 247, 83-94 (2003).

13) Maharaj H, Maharaj DS, Daya S. Acetylsalicylic acid and acetaminophen protect against oxidative neurotoxicity. Metab. Brain Dis., 21, 180-190 (2006).

14) Tripathy D, Grammas P. Acetaminophen protects brain endothelial cells against oxidative stress. Microvasc. Res., 77, 289-296 (2009).

15) Hou C-C, Lin H, Chang C-P, Huang W-T, Lin M-T. Oxidative stress and pyrogenic fever pathogenesis. Eur. J. Pharmacol., 667, 6-12 (2011).

16) Meremikwu M, Oyo-Ita A. Paracetamol for treating fever in children. Cochrane Database Syst. Rev., 2, CD003676 (2002).

17) de Martino M, Chiarugi A. Recent advances in pediatric use of oral paracetamol in fever and pain management. Pain Ther., 4, 149-168 (2015).

18) de Fays L, Van Malderen K, De Smet K, Sawchik J, Verlinden V, Hamdani J, Dogné J-M, Dan B. Use of paracetamol during pregnancy and child neurological development. Dev. Med. Child Neurol., 57, 718-724 (2015).

19) Mian P, Allegaert K, Spriet I, Tibboel D, Petrovic M. Paracetamol in older people: towards evidence-based dosing? Drugs Aging, 35, 603-624 (2018).

20) Rostom A, Dube C, Wells G, Tugwell P, Welch V, Jolicoeur E, McGowan J. Prevention of NSAID-induced gastroduodenal ulcers. Cochrane Database Syst. Rev., 4, CD002296 (2002).

21) Lee A, Cooper MG, Craig JC, Knight JF, Keneally JP. Effects of nonsteroidal anti-inflammatory drugs on postoperative renal function in adults with normal renal function. Cochrane Database Syst. Rev., 2, CD002765 (2007).

22) Dunn MJ, Zambraski EJ. Renal effects of drugs that inhibit prostaglandin synthesis. Kidney Int., 18, 609-622 (1980).

23) Rexrode KM, Buring JE, Glynn RJ, Stampfer MJ, Youngman LD, Gaziano JM. Analgesic use and renal function in men. JAMA, 286, 315-321 (2001).

24) Hiragi S, Yamada H, Tsukamoto $T$, Yoshida K, Kondo N, Matsubara T, Yanagita M, Tamura H, Kuroda T. Acetaminophen administration and the risk of acute kidney injury: a self-controlled case series study. Clin. Epidemiol., 10, 265-276 (2018).

25) Kadowaki D, Sumikawa S, Arimizu K, Taguchi K, Kitamura K, Ishitsuka Y, Narita Y, Irie T, Chuang VTG, Maruyama T, Otagiri
M, Hirata S. Effect of acetaminophen on the progression of renal damage in adenine induced renal failure model rats. Life Sci., 91, 1304-1308 (2012).

26) Duggin GG. Combination analgesic-induced kidney disease: the Australian experience. Am. J. Kidney Dis., 28 (Suppl. 1), S39-S47 (1996).

27) Elseviers MM, De Broe ME. Combination analgesic involvement in the pathogenesis of analgesic nephropathy: the European perspective. Am. J. Kidney Dis., 28 (Suppl. 1), S48-S55 (1996).

28) Elseviers MM, De Broe ME. Analgesic nephropathy: is it caused by multi-analgesic abuse or single substance use? Drug Saf., 20, 15-24 (1999).

29) Mihatsch MJ, Khanlari B, Brunner FP. Obituary to analgesic nephropathy - an autopsy study. Nephrol. Dial. Transplant., 21, 3139-3145 (2006).

30) Nagai J, Uesawa Y, Shimamura R, Kagaya H. Characterization of the adverse effects induced by acetaminophen and nonsteroidal anti-inflammatory drugs based on the analysis of the japanese adverse drug event report database. Clin. J. Pain, 33, 667-675 (2017).

31) Green GA. Understanding NSAIDs: from aspirin to COX-2. Clin. Cornerstone, 3, 50-59 (2001).

32) Carvajal A, Prieto JR, Alvarez Requejo A, Martin Arias LH. Aspirin or acetaminophen? A comparison from data collected by the Spanish Drug Monitoring System. J. Clin. Epidemiol., 49, 255-261 (1996).

33) Lewis SC, Langman MJS, Laporte J-R, Matthews JNS, Rawlins MD, Wiholm B-E. Dose-response relationships between individual nonaspirin nonsteroidal anti-inflammatory drugs (NANSAIDs) and serious upper gastrointestinal bleeding: a meta-analysis based on individual patient data. Br. J. Clin. Pharmacol., 54, 320-326 (2002).

34) Bannwarth B. Gastrointestinal safety of paracetamol: is there any cause for concern? Expert Opin. Drug Saf., 3, 269-272 (2004).

35) McCrae JC, Morrison EE, MacIntyre IM, Dear JW, Webb DJ. Long-term adverse effects of paracetamol - a review. Br. J. Clin. Pharmacol., 84, 2218-2230 (2018).

36) García Rodríguez LA, Hernández-Díaz S. Relative risk of upper gastrointestinal complications among users of acetaminophen and nonsteroidal anti-inflammatory drugs. Epidemiology, 12, 570-576 (2001).

37) González-Pérez A, García Rodríguez LA. Upper gastrointestinal complications among users of paracetamol. Basic Clin. Pharmacol. Toxicol., 98, 297-303 (2006).

38) Kowalski ML, Asero R, Bavbek S, Blanca M, Blanca-Lopez N, Bochenek G, Brockow K, Campo P, Celik G, Cernadas J, Cortellini G, Gomes E, Niżankowska-Mogilnicka E, Romano A, Szczeklik A, Testi S, Torres MJ, Wöhrl S, Makowska J. Classification and practical approach to the diagnosis and management of hypersensitivity to nonsteroidal anti-inflammatory drugs. Allergy, $\mathbf{6 8}$, 1219-1232 (2013).

39) Rajan JP, Wineinger NE, Stevenson DD, White AA. Prevalence of aspirin-exacerbated respiratory disease among asthmatic patients: A meta-analysis of the literature. J. Allergy Clin. Immunol., 135, 676-681.e1 (2015)

40) White AA, Stevenson DD. Aspirin-exacerbated respiratory disease. N. Engl. J. Med., 379, 1060-1070 (2018).

41) Arm JP, O’Hickey SP, Spur BW, Lee TH. Airway responsiveness to histamine and leukotriene E4 in subjects with aspirin-induced asthma. Am. Rev. Respir. Dis., 140, 148-153 (1989).

42) Cowburn AS, Sladek K, Soja J, Adamek L, Nizankowska E, Szczeklik A, Lam BK, Penrose JF, Austen FK, Holgate ST, Sampson AP. Overexpression of leukotriene C4 synthase in bronchial biopsies from patients with aspirin-intolerant asthma. J. Clin. Invest., 101, 834-846 (1998).

43) Fahrenholz JM. Natural history and clinical features of aspirin- 
exacerbated respiratory disease. Clin. Rev. Allergy Immunol., 24, $113-124$ (2003).

44) Sheehan WJ, Mauger DT, Paul IM, et al. NIH/NHLBI AsthmaNet. Acetaminophen versus ibuprofen in young children with mild persistent asthma. N. Engl. J. Med., 375, 619-630 (2016).

45) Fu L-S, Lin C-C, Wei C-Y, Lin C-H, Huang Y-C. Risk of acute exacerbation between acetaminophen and ibuprofen in children with asthma. PeerJ, 7, e6760 (2019).

46) Settipane RA, Stevenson DD. Cross sensitivity with acetaminophen in aspirin-sensitive subjects with asthma. J. Allergy Clin. Immunol., 84, 26-33 (1989).

47) Varner AE, Busse WW, Lemanske RF Jr. Hypothesis: decreased use of pediatric aspirin has contributed to the increasing prevalence of childhood asthma. Ann. Allergy Asthma Immunol., 81, 347-351 (1998).

48) Shaheen SO, Sterne JA, Songhurst CE, Burney PG. Frequent paracetamol use and asthma in adults. Thorax, 55, 266-270 (2000).

49) Barr RG, Wentowski CC, Curhan GC, Somers SC, Stampfer MJ, Schwartz J, Speizer FE, Camargo CA Jr. Prospective study of acetaminophen use and newly diagnosed asthma among women. $\mathrm{Am}$. J. Respir. Crit. Care Med., 169, 836-841 (2004).

50) McKeever TM, Lewis SA, Smit HA, Burney P, Britton JR, Cassano PA. The association of acetaminophen, aspirin, and ibuprofen with respiratory disease and lung function. Am. J. Respir. Crit. Care Med., 171, 966-971 (2005).

51) Thomsen SF, Kyvik KO, Skadhauge L, Steffensen I, Backer V. Intake of paracetamol and risk of asthma in adults. J. Asthma, 45, 675-676 (2008)

52) Farquhar H, Stewart A, Mitchell E, Crane J, Eyers S, Weatherall M, Beasley R. The role of paracetamol in the pathogenesis of asthma. Clin. Exp. Allergy, 40, 32-41 (2010).

53) Etminan M, Sadatsafavi M, Jafari S, Doyle-Waters M, Aminzadeh $\mathrm{K}$, FitzGerald JM. Acetaminophen use and the risk of asthma in children and adults: a systematic review and metaanalysis. Chest, 136, 1316-1323 (2009).

54) Cheelo M, Lodge CJ, Dharmage SC, Simpson JA, Matheson M, Heinrich J, Lowe AJ. Paracetamol exposure in pregnancy and early childhood and development of childhood asthma: a systematic review and meta-analysis. Arch. Dis. Child., 100, 81-89 (2015).

55) Eyers S, Weatherall M, Jefferies S, Beasley R. Paracetamol in pregnancy and the risk of wheezing in offspring: a systematic review and meta-analysis. Clin. Exp. Allergy, 41, 482-489 (2011).

56) Fan G, Wang B, Liu C, Li D. Prenatal paracetamol use and asthma in childhood: A systematic review and meta-analysis. Allergol. Immunopathol. (Madr.), 45, 528-533 (2017).

57) Thiele K, Solano ME, Huber S, Flavell RA, Kessler T, Barikbin R, Jung R, Karimi K, Tiegs G, Arck PC. Prenatal acetaminophen affects maternal immune and endocrine adaptation to pregnancy, induces placental damage, and impairs fetal development in mice. Am. J. Pathol., 185, 2805-2818 (2015).

58) Karimi K, Keßler T, Thiele K, Ramisch K, Erhardt A, Huebener P, Barikbin R, Arck P, Tiegs G. Prenatal acetaminophen induces liver toxicity in dams, reduces fetal liver stem cells, and increases airway inflammation in adult offspring. J. Hepatol., 62, 1085-1091 (2015).

59) Nassini R, Materazzi S, Andrè E, et al. Acetaminophen, via its reactive metabolite $N$-acetyl- $p$-benzo-quinoneimine and transient receptor potential ankyrin-1 stimulation, causes neurogenic inflammation in the airways and other tissues in rodents. FASEB J., 24, 4904-4916 (2010).

60) Shaheen SO, Newson RB, Ring SM, Rose-Zerilli MJ, Holloway JW, Henderson AJ. Prenatal and infant acetaminophen exposure, antioxidant gene polymorphisms, and childhood asthma. J. Allergy Clin. Immunol., 126, 1141-1148.e7 (2010).

61) Perzanowski MS, Miller RL, Tang D, Ali D, Garfinkel RS, Chew
GL, Goldstein IF, Perera FP, Barr RG. Prenatal acetaminophen exposure and risk of wheeze at age 5 years in an urban low-income cohort. Thorax, 65, 118-123 (2010).

62) Smith GJ, Thrall RS, Cloutier MM, Manautou JE, Morris JB. Acetaminophen attenuates house dust mite-induced allergic airway disease in mice. J. Pharmacol. Exp. Ther., 358, 569-579 (2016).

63) Kennedy JL, Kurten RC, McCullough S, Panettieri RA, KoziolWhite C, Jones SM, Caid K, Gill PS, Roberts D, Jaeschke H, McGill MR, James L. Acetaminophen is both bronchodilatory and bronchoprotective in human precision cut lung slice airways. Xenobiotica, 49, 1106-1115 (2019).

64) Lourido-Cebreiro T, Salgado F-J, Valdes L, Gonzalez-Barcala F-J. The association between paracetamol and asthma is still under debate. J. Asthma, 54, 32-38 (2017).

65) Antonucci R, Zaffanello M, Puxeddu E, Porcella A, Cuzzolin L, Pilloni MD, Fanos V. Use of non-steroidal anti-inflammatory drugs in pregnancy: impact on the fetus and newborn. Curr. Drug Metab., 13, 474-490 (2012).

66) El-Khuffash A, Jain A, Corcoran D, Shah PS, Hooper CW, Brown N, Poole SD, Shelton EL, Milne GL, Reese J, McNamara PJ. Efficacy of paracetamol on patent ductus arteriosus closure may be dose dependent: evidence from human and murine studies. Pediatr. Res., 76, 238-244 (2014).

67) Rudolph AM. Effects of aspirin and acetaminophen in pregnancy and in the newborn. Arch. Intern. Med., 141, 358-363 (1981).

68) Simbi KA, Secchieri S, Rinaldo M, Demi M, Zanardo V. In utero ductal closure following near-term maternal self-medication with nimesulide and acetaminophen. J. Obstet. Gynaecol., 22, 440-441 (2002).

69) Olley PM, Coceani F. Prostaglandins and the ductus arteriosus. Annu. Rev. Med., 32, 375-385 (1981).

70) Rostas SE, McPherson CC. Pharmacotherapy for patent ductus arteriosus: current options and outstanding questions. Curr. Pediatr. Rev., 12, 110-119 (2016).

71) Cuzzolin L, Bardanzellu F, Fanos V. The dark side of ibuprofen in the treatment of patent ductus arteriosus: could paracetamol be the solution? Expert Opin. Drug Metab. Toxicol., 14, 855-868 (2018).

72) Hammerman C, Bin-Nun A, Markovitch E, Schimmel MS, Kaplan M, Fink D. Ductal closure with paracetamol: a surprising new approach to patent ductus arteriosus treatment. Pediatrics, 128, e1618-e1621 (2011).

73) Oncel MY, Yurttutan S, Degirmencioglu H, Uras N, Altug N, Erdeve O, Dilmen U. Intravenous paracetamol treatment in the management of patent ductus arteriosus in extremely low birth weight infants. Neonatology, 103, 166-169 (2013).

74) Dang D, Wang D, Zhang C, Zhou W, Zhou Q, Wu H. Comparison of oral paracetamol versus ibuprofen in premature infants with patent ductus arteriosus: a randomized controlled trial. PLOS ONE, 8, e77888 (2013).

75) Oncel MY, Yurttutan S, Erdeve O, Uras N, Altug N, Oguz SS, Canpolat FE, Dilmen U. Oral paracetamol versus oral ibuprofen in the management of patent ductus arteriosus in preterm infants: a randomized controlled trial. J. Pediatr., 164, 510-514.e1 (2014).

76) Härkin P, Härmä A, Aikio O, Valkama M, Leskinen M, Saarela T, Hallman M. Paracetamol Accelerates closure of the ductus arteriosus after premature birth: a randomized trial. J. Pediatr., 177, 72-77.e2 (2016).

77) Dash SK, Kabra NS, Avasthi BS, Sharma SR, Padhi P, Ahmed J. Enteral paracetamol or Intravenous indomethacin for closure of patent ductus arteriosus in preterm neonates: a randomized controlled trial. Indian Pediatr., 52, 573-578 (2015).

78) El-Mashad AE-R, El-Mahdy H, El Amrousy D, Elgendy M. Comparative study of the efficacy and safety of paracetamol, ibuprofen, and indomethacin in closure of patent ductus arteriosus in preterm neonates. Eur. J. Pediatr., 176, 233-240 (2017).

79) Wright CJ. Paracetamol for ductal closure: Inching closer, but cau- 
tiously! J. Pediatr., 198, 4 (2018)

80) van den Anker JN, Allegaert K. Acetaminophen in the neonatal intensive care unit: shotgun approach or silver bullet. J. Pediatr., 198, 10-11 (2018)

81) Bin-Nun A, Fink D, Mimouni FB, Algur N, Hammerman C. Paracetamol serum concentrations in neonates treated enterally for ductal closure: a pilot study. J. Pediatr., 198, 304-307 (2018).

82) Liew Z, Ritz B, Rebordosa C, Lee P-C, Olsen J. Acetaminophen use during pregnancy, behavioral problems, and hyperkinetic disorders. JAMA Pediatr., 168, 313-320 (2014).

83) Cooper M, Langley K, Thapar A. Antenatal acetaminophen use and attention-deficit/hyperactivity disorder: an interesting observed association but too early to infer causality. JAMA Pediatr., 168, 306-307 (2014).

84) Viberg H, Eriksson P, Gordh T, Fredriksson A. Paracetamol (acetaminophen) administration during neonatal brain development affects cognitive function and alters its analgesic and anxiolytic response in adult male mice. Toxicol. Sci., 138, 139-147 (2014).

85) Ostapowicz G, Fontana RJ, Schiødt FV, Larson A, Davern TJ, Han SHB, McCashland TM, Shakil AO, Hay JE, Hynan L, Crippin JS, Blei AT, Samuel G, Reisch J, Lee WM. Results of a prospective study of acute liver failure at 17 tertiary care centers in the United States. Ann. Intern. Med., 137, 947-954 (2002).

86) Reddy KR, Ellerbe C, Schilsky M, Stravitz RT, Fontana RJ, Durkalski V, Lee WM. Determinants of outcome among patients with acute liver failure listed for liver transplantation in the United States. Liver Transpl., 22, 505-515 (2016).

87) Craig DGN, Bates CM, Davidson JS, Martin KG, Hayes PC, Simpson KJ. Overdose pattern and outcome in paracetamol-induced acute severe hepatotoxicity. Br. J. Clin. Pharmacol., 71, 273-282 (2011).

88) Gow PJ, Jones RM, Dobson JL, Angus PW. Etiology and outcome of fulminant hepatic failure managed at an Australian liver transplant unit. J. Gastroenterol. Hepatol., 19, 154-159 (2004).

89) Lee WM. Etiologies of acute liver failure. Semin. Liver Dis., 28, 142-152 (2008).

90) Jaeschke H, Duan L, Akakpo JY, Farhood A, Ramachandran A. The role of apoptosis in acetaminophen hepatotoxicity. Food Chem. Toxicol., 118, 709-718 (2018).

91) Ni H-M, Williams JA, Jaeschke H, Ding W-X. Zonated induction of autophagy and mitochondrial spheroids limits acetaminopheninduced necrosis in the liver. Redox Biol., 1, 427-432 (2013).

92) Corcoran GB, Mitchell JR, Vaishnav YN, Horning EC. Evidence that acetaminophen and $N$-hydroxyacetaminophen form a common arylating intermediate, $N$-acetyl- $p$-benzoquinoneimine. Mol. Pharmacol., 18, 536-542 (1980).

93) Lee SS, Buters JT, Pineau T, Fernandez-Salguero P, Gonzalez FJ. Role of CYP2E1 in the hepatotoxicity of acetaminophen. J. Biol. Chem., 271, 12063-12067 (1996).

94) Zaher H, Buters JT, Ward JM, Bruno MK, Lucas AM, Stern ST, Cohen SD, Gonzalez FJ. Protection against acetaminophen toxicity in CYP1A2 and CYP2E1 double-null mice. Toxicol. Appl. Pharmacol., 152, 193-199 (1998).

95) Cheung $\mathrm{C}, \mathrm{Yu}$ A-M, Ward JM, Krausz KW, Akiyama TE, Feigenbaum L, Gonzalez FJ. The cyp2e1-humanized transgenic mouse: role of cyp2el in acetaminophen hepatotoxicity. Drug Metab. Dispos., 33, 449-457 (2005).

96) Lawson JA, Fisher MA, Simmons CA, Farhood A, Jaeschke H. Inhibition of Fas receptor (CD95)-induced hepatic caspase activation and apoptosis by acetaminophen in mice. Toxicol. Appl. Pharmacol., 156, 179-186 (1999).

97) Jaeschke H, Gujral JS, Bajt ML. Apoptosis and necrosis in liver disease. Liver Int., 24, 85-89 (2004).

98) Bajt ML, Cover C, Lemasters JJ, Jaeschke H. Nuclear translocation of endonuclease $\mathrm{G}$ and apoptosis-inducing factor during acetaminophen-induced liver cell injury. Toxicol. Sci., 94, 217-225
(2006).

99) Bajt ML, Ramachandran A, Yan H-M, Lebofsky M, Farhood A, Lemasters JJ, Jaeschke H. Apoptosis-inducing factor modulates mitochondrial oxidant stress in acetaminophen hepatotoxicity. Toxicol. Sci., 122, 598-605 (2011).

100) Masubuchi Y, Suda C, Horie T. Involvement of mitochondrial permeability transition in acetaminophen-induced liver injury in mice. J. Hepatol., 42, 110-116 (2005).

101) Bruderer R, Bernhardt OM, Gandhi T, Miladinović SM, Cheng L-Y, Messner S, Ehrenberger T, Zanotelli V, Butscheid Y, Escher C, Vitek O, Rinner O, Reiter L. Extending the limits of quantitative proteome profiling with data-independent acquisition and application to acetaminophen-treated three-dimensional liver microtissues. Mol. Cell. Proteomics, 14, 1400-1410 (2015).

102) Ramachandran A, Jaeschke H. Acetaminophen toxicity: novel insights into mechanisms and future perspectives. Gene Expr., 18, 19-30 (2018).

103) Beales D, McLean AE. Protection in the late stages of paracetamol-induced liver cell injury with fructose, cyslosporin A and trifluoperazine. Toxicology, 107, 201-208 (1996).

104) Aritomi K, Ishitsuka Y, Tomishima Y, Shimizu D, Abe N, Shuto T, Irikura M, Kai H, Irie T. Evaluation of three-dimensional cultured HepG2 cells in a nano culture plate system: an in vitro human model of acetaminophen hepatotoxicity. J. Pharmacol. Sci., 124, 218-229 (2014).

105) Hanawa N, Shinohara M, Saberi B, Gaarde WA, Han D, Kaplowitz N. Role of JNK translocation to mitochondria leading to inhibition of mitochondria bioenergetics in acetaminophen-induced liver injury. J. Biol. Chem., 283, 13565-13577 (2008).

106) Bajt ML, Farhood A, Lemasters JJ, Jaeschke H. Mitochondrial bax translocation accelerates DNA fragmentation and cell necrosis in a murine model of acetaminophen hepatotoxicity. J. Pharmacol. Exp. Ther., 324, 8-14 (2008).

107) Ramachandran A, Lebofsky M, Baines CP, Lemasters JJ, Jaeschke H. Cyclophilin D deficiency protects against acetaminopheninduced oxidant stress and liver injury. Free Radic. Res., 45, 156-164 (2011).

108) LoGuidice A, Boelsterli UA. Acetaminophen overdose-induced liver injury in mice is mediated by peroxynitrite independently of the cyclophilin D-regulated permeability transition. Hepatology, 54, 969-978 (2011).

109) Sakaida I, Kayano K, Wasaki S, Nagatomi A, Matsumura Y, Okita $\mathrm{K}$. Protection against acetaminophen-induced liver injury in vivo by an iron chelator, deferoxamine. Scand. J. Gastroenterol., 30, 61-67 (1995).

110) $\mathrm{Hu}$ J, Kholmukhamedov A, Lindsey CC, Beeson CC, Jaeschke H, Lemasters JJ. Translocation of iron from lysosomes to mitochondria during acetaminophen-induced hepatocellular injury: Protection by starch-desferal and minocycline. Free Radic. Biol. Med., 97, 418-426 (2016).

111) Hinson JA, Bucci TJ, Irwin LK, Michael SL, Mayeux PR. Effect of inhibitors of nitric oxide synthase on acetaminophen-induced hepatotoxicity in mice. Nitric Oxide, 6, 160-167 (2002).

112) Knight TR, Ho Y-S, Farhood A, Jaeschke H. Peroxynitrite is a critical mediator of acetaminophen hepatotoxicity in murine livers: protection by glutathione. J. Pharmacol. Exp. Ther., 303, 468-475 (2002).

113) Ramachandran A, Visschers RGJ, Duan L, Akakpo JY, Jaeschke H. Mitochondrial dysfunction as a mechanism of drug-induced hepatotoxicity: current understanding and future perspectives. $J$. Clin. Transl. Res., 4, 75-100 (2018).

114) Ni H-M, McGill MR, Chao X, Du K, Williams JA, Xie Y, Jaeschke H, Ding W-X. Removal of acetaminophen protein adducts by autophagy protects against acetaminophen-induced liver injury in mice. J. Hepatol., 65, 354-362 (2016).

115) Wang H, Ni H-M, Chao X, Ma X, Rodriguez YA, Chavan H, 
Wang S, Krishnamurthy P, Dobrowsky R, Xu D-X, Jaeschke H, Ding W-X. Double deletion of PINK1 and Parkin impairs hepatic mitophagy and exacerbates acetaminophen-induced liver injury in mice. Redox Biol., 22, 101148 (2019).

116) $\mathrm{Du} \mathrm{K}$, Farhood A, Jaeschke H. Mitochondria-targeted antioxidant Mito-Tempo protects against acetaminophen hepatotoxicity. Arch. Toxicol., 91, 761-773 (2017).

117) Du K, Ramachandran A, Weemhoff JL, Woolbright BL, Jaeschke AH, Chao X, Ding W-X, Jaeschke H. Mito-tempo protects against acute liver injury but induces limited secondary apoptosis during the late phase of acetaminophen hepatotoxicity. Arch. Toxicol., 93, 163-178 (2019).

118) Du K, Ramachandran A, Weemhoff JL, Chavan H, Xie Y, Krishnamurthy P, Jaeschke H. Editor's Highlight: Metformin protects against acetaminophen hepatotoxicity by attenuation of mitochondrial oxidant stress and dysfunction. Toxicol. Sci., 154, 214-226 (2016).

119) Lee KK, Imaizumi N, Chamberland SR, Alder NN, Boelsterli UA. Targeting mitochondria with methylene blue protects mice against acetaminophen-induced liver injury. Hepatology, 61, 326-336 (2015).

120) Shi X, Bai H, Zhao M, Li X, Sun X, Jiang H, Fu A. Treatment of acetaminophen-induced liver injury with exogenous mitochondria in mice. Transl. Res., 196, 31-41 (2018).

121) Du K, McGill MR, Xie Y, Bajt ML, Jaeschke H. Resveratrol prevents protein nitration and release of endonucleases from mitochondria during acetaminophen hepatotoxicity. Food Chem. Toxicol., 81, 62-70 (2015).

122) Barbier-Torres L, Iruzubieta $\mathrm{P}$, Fernández-Ramos $\mathrm{D}$, et al. The mitochondrial negative regulator MCJ is a therapeutic target for acetaminophen-induced liver injury. Nat. Commun., 8, 2068 (2017).

123) Du K, Ramachandran A, McGill MR, Mansouri A, Asselah $T$, Farhood A, Woolbright BL, Ding W-X, Jaeschke H. Induction of mitochondrial biogenesis protects against acetaminophen hepatotoxicity. Food Chem. Toxicol., 108 (Pt A), 339-350 (2017).

124) Davis RJ. Signal transduction by the JNK group of MAP kinases. Cell, 103, 239-252 (2000).

125) Waetzig V, Herdegen T. Context-specific inhibition of JNKs: overcoming the dilemma of protection and damage. Trends Pharmacol. Sci., 26, 455-461 (2005).

126) Wagner EF, Nebreda AR. Signal integration by JNK and p38 MAPK pathways in cancer development. Nat. Rev. Cancer, 9, 537-549 (2009)

127) Du K, Xie Y, McGill MR, Jaeschke H. Pathophysiological significance of c-jun N-terminal kinase in acetaminophen hepatotoxicity. Expert Opin. Drug Metab. Toxicol., 11, 1769-1779 (2015).

128) Gunawan BK, Liu Z-X, Han D, Hanawa N, Gaarde WA, Kaplowitz N. c-Jun N-terminal kinase plays a major role in murine acetaminophen hepatotoxicity. Gastroenterology, 131, 165-178 (2006).

129) Henderson NC, Pollock KJ, Frew J, Mackinnon AC, Flavell RA, Davis RJ, Sethi T, Simpson KJ. Critical role of c-jun (NH2) terminal kinase in paracetamol-induced acute liver failure. Gut, $\mathbf{5 6}$ 982-990 (2007).

130) Latchoumycandane C, Goh CW, Ong MMK, Boelsterli UA. Mitochondrial protection by the JNK inhibitor leflunomide rescues mice from acetaminophen-induced liver injury. Hepatology, 45, 412-421 (2007).

131) Nakagawa $H$, Maeda $S$, Hikiba $Y$, Ohmae $T$, Shibata W, Yanai A, Sakamoto K, Ogura K, Noguchi T, Karin M, Ichijo H, Omata M. Deletion of apoptosis signal-regulating kinase 1 attenuates acetaminophen-induced liver injury by inhibiting c-Jun N-terminal kinase activation. Gastroenterology, 135, 1311-1321 (2008).

132) Xie Y, Ramachandran A, Breckenridge DG, Liles JT, Lebofsky M, Farhood A, Jaeschke H. Inhibitor of apoptosis signal-regulating kinase 1 protects against acetaminophen-induced liver injury. Toxicol. Appl. Pharmacol., 286, 1-9 (2015).
133) Yang X, Zhan Y, Sun Q, Xu X, Kong Y, Zhang J. Adenosine 5 '-monophosphate blocks acetaminophen toxicity by increasing ubiquitination-mediated ASK1 degradation. Oncotarget, 8, 62736282 (2017).

134) Shinohara M, Ybanez MD, Win S, Than TA, Jain S, Gaarde WA, Han D, Kaplowitz N. Silencing glycogen synthase kinase-3beta inhibits acetaminophen hepatotoxicity and attenuates JNK activation and loss of glutamate cysteine ligase and myeloid cell leukemia sequence 1. J. Biol. Chem., 285, 8244-8255 (2010).

135) Sharma M, Gadang V, Jaeschke A. Critical role for mixed-lineage kinase 3 in acetaminophen-induced hepatotoxicity. Mol. Pharmacol., 82, 1001-1007 (2012).

136) Bourdi M, Korrapati MC, Chakraborty M, Yee SB, Pohl LR. Protective role of c-Jun N-terminal kinase 2 in acetaminopheninduced liver injury. Biochem. Biophys. Res. Commun., 374, 6-10 (2008).

137) Shimizu D, Ishitsuka Y, Miyata K, Tomishima Y, Kondo Y, Irikura M, Iwawaki T, Oike Y, Irie T. Protection afforded by pre- or post-treatment with 4-phenylbutyrate against liver injury induced by acetaminophen overdose in mice. Pharmacol. Res., 87, 26-41 (2014).

138) Uzi D, Barda L, Scaiewicz V, Mills M, Mueller T, GonzalezRodriguez A, Valverde AM, Iwawaki T, Nahmias Y, Xavier R, Chung RT, Tirosh B, Shibolet O. CHOP is a critical regulator of acetaminophen-induced hepatotoxicity. J. Hepatol., 59, 495-503 (2013).

139) Cubero FJ, Zoubek ME, Hu W, Peng J, Zhao G, Nevzorova YA, Al Masaoudi M, Bechmann LP, Boekschoten MV, Muller M, Preisinger C, Gassler N, Canbay AE, Luedde T, Davis RJ, Liedtke C, Trautwein C. Combined activities of JNK1 and JNK2 in hepatocytes protect against toxic liver injury. Gastroenterology, 150, 968-981 (2016).

140) Ni H-M, Bockus A, Boggess N, Jaeschke H, Ding W-X. Activation of autophagy protects against acetaminophen-induced hepatotoxicity. Hepatology, 55, 222-232 (2012).

141) Igusa Y, Yamashina S, Izumi K, Inami Y, Fukada H, Komatsu M, Tanaka K, Ikejima K, Watanabe S. Loss of autophagy promotes murine acetaminophen hepatotoxicity. J. Gastroenterol., 47, 433443 (2012).

142) Wu CT, Sheu ML, Tsai KS, Chiang CK, Liu SH. Salubrinal, an eIF2 $\alpha$ dephosphorylation inhibitor, enhances cisplatin-induced oxidative stress and nephrotoxicity in a mouse model. Free Radic. Biol. Med., 51, 671-680 (2011).

143) Tanaka Y, Ishitsuka Y, Hayasaka M, Yamada Y, Miyata K, Endo M, Kondo Y, Moriuchi H, Irikura M, Tanaka K, Mizushima T, Oike Y, Irie T. The exacerbating roles of CCAAT/enhancerbinding protein homologous protein (CHOP) in the development of bleomycin-induced pulmonary fibrosis and the preventive effects of tauroursodeoxycholic acid (TUDCA) against pulmonary fibrosis in mice. Pharmacol. Res., 99, 52-62 (2015).

144) Yao Y, Wang Y, Zhang Z, He L, Zhu J, Zhang M, He X, Cheng Z, Ao Q, Cao Y, Yang P, Su Y, Zhao J, Zhang S, Yu Q, Ning Q, Xiang X, Xiong W, Wang C-Y, Xu Y. Chop deficiency protects mice against bleomycin-induced pulmonary fibrosis by attenuating M2 macrophage production. Mol. Ther., 24, 915-925 (2016).

145) Ayaub EA, Kolb PS, Mohammed-Ali Z, Tat V, Murphy J, Bellaye P-S, Shimbori C, Boivin FJ, Lai R, Lynn EG, Lhoták S, Bridgewater D, Kolb MR, Inman MD, Dickhout JG, Austin RC, Ask K. GRP78 and CHOP modulate macrophage apoptosis and the development of bleomycin-induced pulmonary fibrosis. J. Pathol., 239, 411-425 (2016).

146) Burman A, Kropski JA, Calvi CL, Serezani AP, Pascoalino BD, Han W, Sherrill T, Gleaves L, Lawson WE, Young LR, Blackwell TS, Tanjore H. Localized hypoxia links ER stress to lung fibrosis through induction of $\mathrm{C} / \mathrm{EBP}$ homologous protein. JCI Insight, $\mathbf{3}$, 99543 (2018). 
147) Nagy G, Kardon T, Wunderlich L, Szarka A, Kiss A, Schaff Z, Bánhegyi G, Mandl J. Acetaminophen induces ER dependent signaling in mouse liver. Arch. Biochem. Biophys., 459, 273-279 (2007).

148) Nagy G, Szarka A, Lotz G, Dóczi J, Wunderlich L, Kiss A, Jemnitz K, Veres Z, Bánhegyi G, Schaff Z, Sümegi B, Mandl J. BGP-15 inhibits caspase-independent programmed cell death in acetaminophen-induced liver injury. Toxicol. Appl. Pharmacol., 243, 96-103 (2010).

149) Tomishima Y, Ishitsuka Y, Matsunaga N, Nagatome M, Furusho $\mathrm{H}$, Irikura $\mathrm{M}$, Ohdo S, Irie T. Ozagrel hydrochloride, a selective thromboxane $\mathrm{A}_{2}$ synthase inhibitor, alleviates liver injury induced by acetaminophen overdose in mice. BMC Gastroenterol., 13, 21 (2013).

150) Kusama H, Kon K, Ikejima K, Arai K, Aoyama T, Uchiyama A, Yamashina S, Watanabe S. Sodium 4-phenylbutyric acid prevents murine acetaminophen hepatotoxicity by minimizing endoplasmic reticulum stress. J. Gastroenterol., 52, 611-622 (2017).

151) Paridaens A, Raevens S, Colle I, Bogaerts E, Vandewynckel Y-P,
Verhelst X, Hoorens A, van Grunsven LA, Van Vlierberghe H, Geerts A, Devisscher L. Combination of tauroursodeoxycholic acid and $N$-acetylcysteine exceeds standard treatment for acetaminophen intoxication. Liver Int., 37, 748-756 (2017).

152) Hur KY, So J-S, Ruda V, Frank-Kamenetsky M, Fitzgerald K, Koteliansky V, Iwawaki T, Glimcher LH, Lee A-H. IRE1 $\alpha$ activation protects mice against acetaminophen-induced hepatotoxicity. $J$. Exp. Med., 209, 307-318 (2012).

153) Torres S, Baulies A, Insausti-Urkia N, Alarcón-Vila C, Fucho R, Solsona-Vilarrasa E, Núñez S, Robles D, Ribas V, Wakefield L, Grompe M, Lucena MI, Andrade RJ, Win S, Aung TA, Kaplowitz N, García-Ruiz C, Fernández-Checa JC. Endoplasmic reticulum stress-induced upregulation of STARD1 promotes acetaminopheninduced acute liver failure. Gastroenterology, 157, 552-568 (2019).

154) van Puijenbroek EP, Bate A, Leufkens HGM, Lindquist M, Orre R, Egberts ACG. A comparison of measures of disproportionality for signal detection in spontaneous reporting systems for adverse drug reactions. Pharmacoepidemiol. Drug Saf., 11, 3-10 (2002). 